\title{
Combination of cold drawing and cryogenic turning for modifying surface morphology of metastable austenitic AISI 347 steel
}

\author{
Hendrik Hotz ${ }^{1}$ (D) Benjamin Kirsch ${ }^{1} \cdot$ Steven Becker $^{2} \cdot$ Ralf Müller $^{2} \cdot$ Jan C. Aurich ${ }^{1}$
}

Received: 21 December 2018/Revised: 11 March 2019/Accepted: 19 March 2019/Published online: 27 August 2019

(C) The Author(s) 2019

\begin{abstract}
The application of components often depends to a large extent on the properties of the surface layer. A novel process chain for the production of components with a hardened surface layer from metastable austenitic steel was presented. The investigated metastable austenitic AISI 347 steel was cold-drawn in solution annealed condition at cryogenic temperatures for pre-hardening, followed by post-hardening via cryogenic turning. The increase in hardness in both processes was due to strain hardening and deformation-induced phase transformation from $\gamma$-austenite to $\alpha^{\prime}$-martensite. Cryogenic turning experiments were carried out with solution annealed AISI 347 steel as well as with solution annealed and subsequently cold-drawn AISI 347 steel. The thermomechanical load of the workpiece surface layer during the turning process as well as the resulting surface morphology was characterized. The forces and temperatures were higher in turning the cold-drawn AISI 347 steel than turning the solution annealed AISI 347 steel. After cryogenic turning of the solution annealed material, deformation-induced phase transformation and a significant increase in hardness were detected in the near-surface layer. In contrast, no additional phase transformation was observed after cryogenic turning of the cold-drawn AISI 347 steel. The maximum hardness in the surface layer was similar, whereas the hardness in the core of the cold-drawn AISI 347 steel was higher compared to that in the solution annealed AISI 347 steel.
\end{abstract}

Keywords Surface layer hardening · Cryogenic turning · Cold drawing · Metastable austenitic steel · Deformation-induced phase transformation

\section{Introduction}

The first austenitic Cr-Ni steel was developed by Maurer and Strauss at the Friedrich Krupp AG and patented in 1912 [1]. Based on the chemical composition of the "Versuchsschmelze 2 Austenit" (V2A) developed at that time, numerous nuances of this metastable austenitic steel exist today. Due to their good mechanical properties and their high corrosion resistance in particular, metastable austenitic steels are widely used in the chemical

Hendrik Hotz

hendrik.hotz@mv.uni-kl.de

1 Institute for Manufacturing Technology and Production Systems, University of Kaiserslautern, 67663 Kaiserslautern, Germany

2 Institute of Applied Mechanics, University of Kaiserslautern, 67663 Kaiserslautern, Germany and petrochemical industries, the food industry, automotive industry and medical technology, among others [2, 3].

The conventional process chain in the manufacture of metastable austenitic steel components usually begins with the casting of the melt in a continuous casting process. After the strands have solidified, they are cut to size. Depending on the geometry of the component, the cast blocks are further processed using various forming processes [4]. Subsequently, the semi-finished products are solution annealed at $1270-1420 \mathrm{~K}$ and quenched in water, air or helium in order to adjust the grain dimension, crystallographic orientation, phase fraction and distribution of chemical elements in the material [5-7]. Then, the final component geometry is achieved by a machining process. Metastable austenitic steels are characterized by a relatively low hardness in the solution annealed condition. Thus, a subsequent process for surface layer hardening is often necessary, since the application behavior of a component is decisively determined by the properties of its 
surface layer [8]. Shaft counter surfaces for radial shafts, for example, are exposed to very high tribological loads. Therefore, these components must have a high surface hardness and sufficient bulk toughness to ensure optimum performance, low wear and thus a long service life [9]. It has been proven that an increase in hardness in metastable austenitic steels leads to a reduction in wear $[10,11]$. A higher surface layer hardness also leads to a better fatigue behavior of cyclically stressed components, because the crack initiation is hampered and the crack propagation is slowed down [12-14].

In metastable austenitic steels, strain hardening mechanisms such as twin formation, increased dislocation density and grain refinement [15-19], as well as deformation-induced phase transformation from $\gamma$-austenite to $\varepsilon$ - and $\alpha^{\prime}$ martensite [20-22] lead to an increase in hardness as well as in tensile and yield strength. In order to achieve this deformation-induced phase transformation, sufficiently high strains must be present at sufficiently low temperatures in order to provide the required difference in free energy [23-25]. If the temperature is below the $M_{\mathrm{s}}$-temperature, the required free energy is achieved without mechanical load and a purely thermal phase transformation of austenite into martensite occurs [26]. With rising temperatures, a higher mechanical load and thus a higher strain must be applied in order to reach the minimum free energy required for the martensitic phase transformation. At a constant temperature, the $\alpha^{\prime}$-martensite content increases with increasing equivalent strain in the form of a sigmoidal function [23, 27]. The required strains and temperatures depend on the austenite stability of the material, which depends on factors such as the chemical composition $[28,29]$ and the grain size $[30,31]$. The strain hardening mechanisms and the generation of deformation-induced martensite can be superimposed to produce surface layers with higher maximum hardness and hardness penetration depth [32].

There are numerous hardening processes at room temperature or below, which exploit these mechanisms in order to increase the hardness, especially in the surface layer. When characterizing the acting loads, these can be divided into processes with mechanical main effect, processes with thermal main effect by means of deep cryogenic treatment, and processes based on a combination of thermal and mechanical effects [33].

Among the most common hardening processes in industry are those with the mechanical main effect, which are carried out subsequent to the machining and generally represent the final step in the conventional process chain for the production of austenitic steel components with a hardened surface layer. Commonly used mechanical hardening processes are shot peening [34], machine hammer peening [35] and burnishing processes like deep rolling [36]. These processes have in common that they result into a plastic deformation in the workpiece surface layer and thus to strain hardening. In addition, it is possible to induce a phase transformation from metastable $\gamma$ austenite into $\varepsilon$ - and $\alpha^{\prime}$-martensite. Deformation-induced phase transformation has already been observed in the surface layer of metastable austenitic steels after rolling [37] and shot peening [14, 38] processes at room temperature, when the deformation in the surface layer was sufficiently high.

Thermal hardening of metastable austenitic steels below room temperature is referred as deep cryogenic treatment. In this process with thermal main effect, the material is placed in a cryogenic medium (mostly liquid nitrogen $\mathrm{LN}_{2}$ at approximate $77 \mathrm{~K}$ ). If the temperature of the cryogen is lower than the $M_{\mathrm{s}}$ temperature of the metastable austenitic steel, a purely thermal phase transformation of austenite into martensite occurs [26]. However, this process is usually only carried out on tool steels after the quenching and tempering process in order to reduce the content of retained austenite [39, 40]. For metastable austenitic steels, this procedure is not practicable for industrial applications [41]. Although thermally induced martensite formation occurs, strain hardening does not take place, because no deformation is applied either. The hardness of $\alpha^{\prime}$-martensite essentially depends on the content of the interstitial carbon atom, which distorts the lattice. However, the carbon content is low in metastable austenitic $\mathrm{Cr}-\mathrm{Ni}$ steels and so is the increase in hardness [21, 42].

More pronounced increases in hardness can be achieved by hardening processes with combined thermal and mechanical effects. For example, cryogenic shot peening leads to higher proportions of deformation-induced $\alpha^{\prime}$ martensite and also more pronounced increases in hardness compared to shot peening at room temperature [43]. In the same way, cryogenic cold rolling also leads to a higher content of $\alpha^{\prime}$-martensite and thus a higher hardness compared to cold rolling at room temperature [44]. Repeated cold rolling and higher deformation favor strain hardening and deformation-induced phase transformation, stronger elongated grains and higher tensile strength [45-47]. Comparative investigations [27] in which the metastable austenitic AISI 304 steel was cold-rolled and cold-drawn showed that the cold-drawn material had a higher $\alpha^{\prime}$-martensite content at the same equivalent strain compared to the cold-rolled AISI 304 steel. Due to the different strain fields, it was concluded that mainly onedirectional deformation twins in the cold-rolled AISI 304 steel and two kinds of twins with different twin planes in the cold-drawn material were formed. Thus, the colddrawn AISI 304 steel also had more martensite nucleation points, which also increased the content of deformationinduced $\alpha^{\prime}$-martensite with the same equivalent strain. 
Another method for the hardening of metastable austenitic steels utilizing both thermal and mechanical effects is cryogenic turning. In contrast to the methods mentioned above, cryogenic turning integrates the surface layer hardening into the cutting process [48]. Thus, an additional hardening processes are rendered obsolete, resulting in a shorter and thus more economical process chain. In this process, the surface hardening also occurs due to a superposition of strain hardening and the generation of deformation-induced $\varepsilon$ - and $\alpha^{\prime}$-martensite. As for the other hardening processes, the cryogenic turning process must be designed in such a way that the lowest possible temperatures and the highest possible mechanical loads are present in the workpiece surface layer. In the turning process, the low temperatures are achieved by means of a cryogenic cooling system and low cutting speeds [49, 50]. High passive forces lead to pronounced deformations of the surface layer. High feed rates and tools with a chamfered or strongly rounded cutting edge can be used to ensure high passive forces $[50,51]$.

\section{Workpiece material and cryogenic pretreatment}

Components made of metastable austenitic steel are usually hardened by means of shot peening after a conventional machining process (see Fig. 1a). In this paper, a novel approach for the hardening of metastable austenitic steels is introduced, where two hardening processes with thermal and mechanical effects are combined in one process chain. The first hardening process, cryogenic cold drawing, will be conducted prior to machining as a pretreatment, and the second hardening process is integrated into the machining process, by means of cryogenic turning. Even though this does extend the process chain, we intended to investigate whether it is possible to produce components with a more pronounced surface layer hardening by combining these two hardening processes. Based on the state of the art, the most efficient pretreatment of metastable austenitic steel is a cold drawing process under deep cryogenic temperatures, which is therefore applied in this study. Cryogenic turning experiments are carried out with solution annealed AISI 347 steel (see Fig. 1b) and solution annealed and then colddrawn AISI 347 steel (see Fig. 1c), utilizing a well proven experimental setup from earlier investigations [52]. The thermomechanical loads occurring in the surface layer during the turning experiments are characterized. The resulting surface morphology is investigated and evaluated with regard to the topography, as well as the metallurgical and mechanical subsurface properties.

Metastable austenitic AISI 347 steel was used for the investigations. Based on the chemical composition (see
Table 1), the $M_{\mathrm{d} 30}$-temperature was calculated to $319 \mathrm{~K}$ according to Angel [28]. At the $M_{\mathrm{d} 30}$-temperature, 50\% $\alpha^{\prime}$ martensite is formed when $30 \%$ plastic strain is applied. Thus, the $M_{\mathrm{d} 30}$-temperature is a suitable parameter for evaluating the susceptibility of a metastable austenitic steel regarding the deformation-induced phase transformation.

The investigated metastable austenitic AISI 347 steel was solution annealed at $1323 \mathrm{~K}$ for $35 \mathrm{~min}$ and then quenched in helium atmosphere. The cold drawing of the solution annealed rod material was carried out on a tensile testing machine. The rods were each first stored for at least $10 \mathrm{~min}$ in liquid nitrogen to ensure that they were completely cooled to $77 \mathrm{~K}$. After that, they were drawn forcecontrolled on the tensile testing machine with a nominal load of $510 \mathrm{MPa}$. This load was chosen because it was significantly above the yield strength (225 MPa [53]), and thus, during the cold drawing process, plastic deformation and consequently deformation-induced phase transformation occurred. Nevertheless, this load of $510 \mathrm{MPa}$ was below the ultimate tensile strength (603 MPa [53]), so that the rods did not break. The solution annealed rod material as well as the rod material solution annealed and then pretreated by cryogenic cold drawing (hereinafter referred to as "cold-drawn") with an initial diameter of $25 \mathrm{~mm}$ was machined to $14.4 \mathrm{~mm}$ in a conventional turning process.

The microstructure of the exclusively solution annealed AISI 347 steel (see Fig. 2a) exhibited several twin grain boundaries after contrasting with V2A etching agent, which are typical for austenitic materials. Figure $2 \mathrm{~b}$ shows the microstructure of the AISI 347 steel after cold drawing. Due to the Beraha II etching agent, the martensite was contrasted black, while the austenite remained white. It became apparent that numerous martensitic needles and some completely martensitic grains were present due to the cold drawing process. Pure austenitic grains were no longer present. The hardness of the solution annealed AISI 347 steel was 210 HV0.01, while the cold-drawn AISI 347 steel had a hardness of $280 \mathrm{HV} 0.01$.

\section{Experimental setup}

The cryogenic turning experiments were carried out on a CNC (computerized numerical control) lathe. Tools and parameter settings were adapted according to the experimental setup from previous experiments [52], with which the thermomechanical loads in the surface layer can be adjusted in a favorable way regarding phase transformation and strain hardening. The feed travel was $18 \mathrm{~mm}$, and the final diameter was $14 \mathrm{~mm}$. Carbon dioxide $\left(\mathrm{CO}_{2}\right)$ was used as cryogenic coolant which was stored in a gas cylinder at room temperature at approximately 5.7 $\mathrm{MPa}$ [49]. The $\mathrm{CO}_{2}$ was extracted from the liquid phase and supplied via two 
(a) Conventional process chain
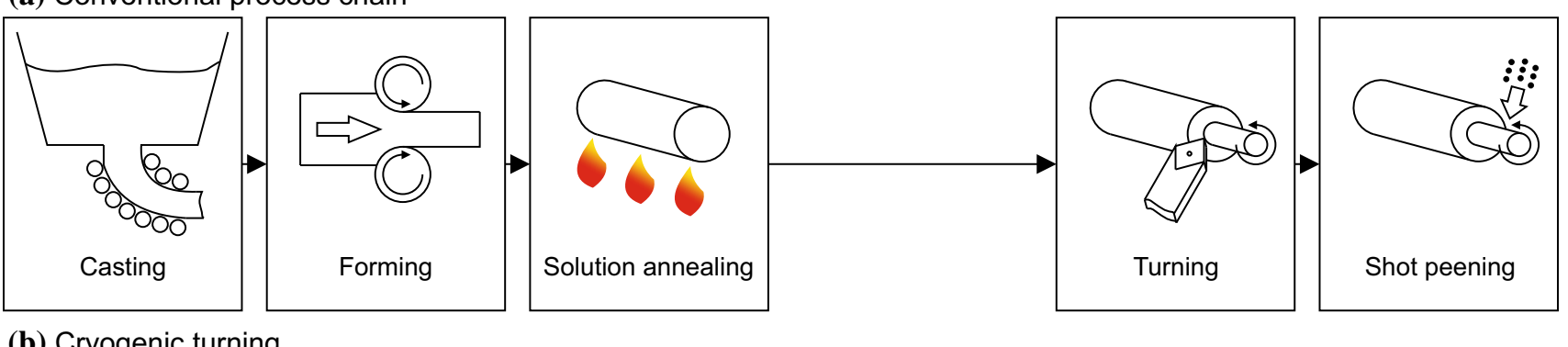

(b) Cryogenic turning
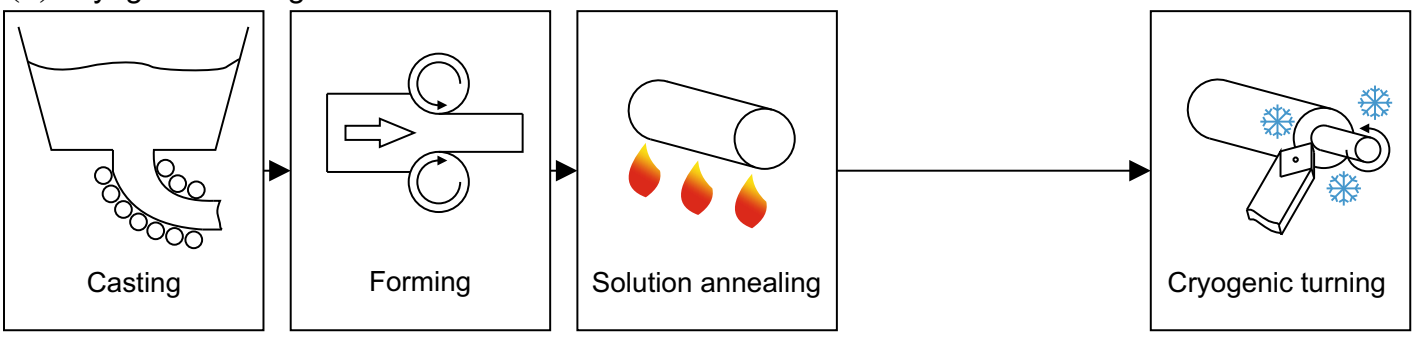

(c) Cold drawing and cryogenic turning
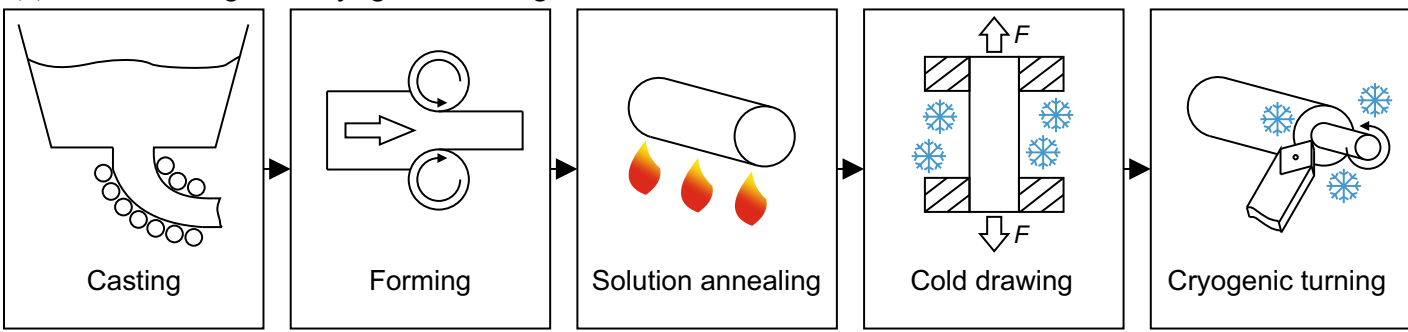

Fig. 1 Process chains for manufacture of components from metastable austenitic steels with hardened surface layer

Table 1 Chemical composition of AISI 347 steel (wt.\%)

\begin{tabular}{llllllllll}
\hline $\mathrm{C}$ & $\mathrm{Cr}$ & $\mathrm{Ni}$ & $\mathrm{N}$ & $\mathrm{Nb}$ & $\mathrm{Mn}$ & $\mathrm{Mo}$ & $\mathrm{Si}$ & $\mathrm{Cu}$ & $\mathrm{Fe}$ \\
\hline 0.021 & 17.19 & 9.44 & 0.022 & 0.38 & 1.55 & 0.23 & 0.59 & 0.11 & Balance \\
\hline
\end{tabular}

(a)

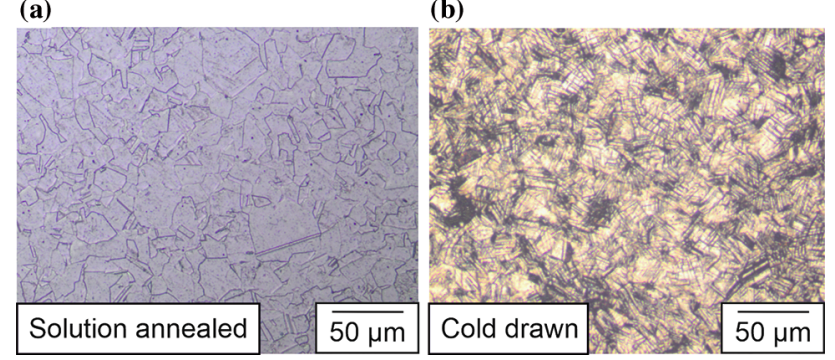

Fig. 2 Optical microsections of metastable austenitic AISI 347 steel after solution annealing (a) and cold drawing (b)

nozzles to the turning process. One nozzle served for precooling of the workpiece from the rake face direction, and the other nozzle supplied the $\mathrm{CO}_{2}$ from flank face direction into the cutting zone (see Fig. 3). At the nozzle exit, a phase transformation of the liquid $\mathrm{CO}_{2}$ into a bi-phase

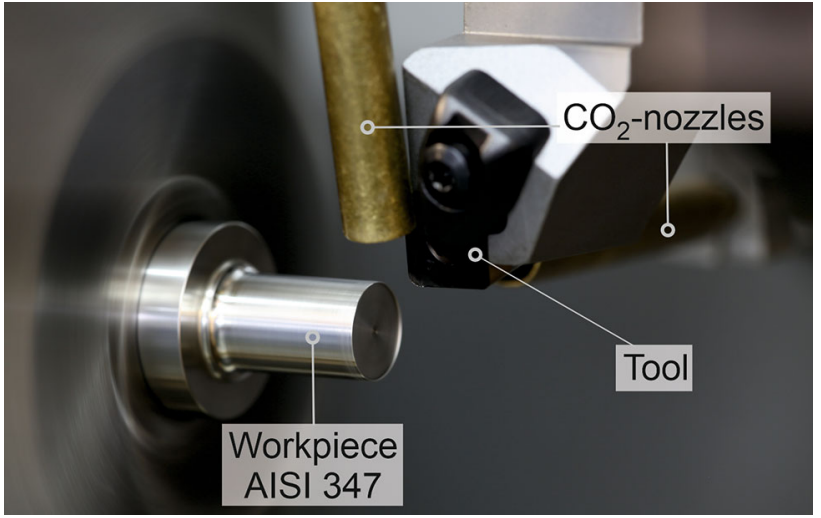

Fig. 3 Cryogenic turning process

solid-gas mixture occurs due to the expansion. The expansion in combination with the Joule-Thompson effect 
leads to a temperature decrease to approximately $194.6 \mathrm{~K}$, which is the sublimation point at standard atmospheric pressure [54]. This provided sufficiently low temperatures in order to realize the deformation-induced phase transformation in the workpiece surface layer. The nozzles had an exit diameter of $10 \mathrm{~mm}$, resulting into a mass flow rate of $1.75 \mathrm{~kg} / \mathrm{min}$ per nozzle. The $\mathrm{CO}_{2}$ cooling system was activated automatically with the numerical control program in order to ensure uniform test conditions.

A low cutting speed of $v_{\mathrm{c}}=30 \mathrm{~m} / \mathrm{min}$ was chosen to realize low temperatures in the cutting zone, which in turn should lead to a pronounced phase transformation from austenite to martensite and consequently to a strong surface layer hardening. The depth of cut was kept constant at $a_{\mathrm{p}}=0.2 \mathrm{~mm}$. Previous study [55] has shown that a variation of the feed significantly affects the passive forces and consequently the resulting surface morphology. Thus, in this paper, the feed rate $(f)$ was also varied $\left(f_{1}=0.15 \mathrm{~mm} /\right.$ rev; $f_{2}=0.35 \mathrm{~mm} / \mathrm{rev}$ ) in order to investigate its influence on the differences in thermomechanical load and resulting surface morphology depending on the initial state of the workpiece material. To ensure sufficient statistics, turning experiments were carried out on three workpieces for each test point.

Chamfered indexable inserts (CNMA 120416 T02020) with an approximately $20-\mu \mathrm{m}$-thick multilayer coating $\left(\mathrm{TiN} / \mathrm{TiCN} / \mathrm{Al}_{2} \mathrm{O}_{3}\right)$ were used. The clearance angle was $\alpha=6^{\circ}$, and the rake angle $\gamma$ and the tool cutting edge inclination $\lambda$ were both $-6^{\circ}$. The chamfer reduced the effective rake angle to approximately $\gamma_{\text {eff }}=-26^{\circ}$ in the whole cutting cross section, thus increasing the passive forces and consequently promoting deformation-induced martensite formation during the turning process. A large corner radius of $r_{\varepsilon}=1.6 \mathrm{~mm}$ was used as this also leads to higher passive forces. A new insert was used for each workpiece in order to minimize the influence of wear.

During the cryogenic turning process, the process forces were measured with a piezoelectric three-component dynamometer. For temperature measurement, a high speed thermography system was used, which was positioned outside the CNC lathe. As the cutting zone itself was not accessible for thermographic measurements, the surface temperature was measured after a $3 / 4$ workpiece rotation. Although the determination of the absolute temperature in the cutting zone was not possible, this measurement method allowed for the comparison of the thermal load of different test points with each other. Further information for the determination of the temperatures in the cryogenic turning process can be found in Ref. [56].

The solution annealed as well as the cold-drawn AISI 347 steel was measured before and after the cryogenic turning process with a magnetic sensor (Ferritscope ${ }^{\mathrm{TM}}$ ). With this sensor, it was possible to detect ferromagnetic phase fractions down to a depth of approximately $3 \mathrm{~mm}$ [57]. The $\alpha^{\prime}$-martensite content in the workpiece surface layer can be determined from the measurement signal by multiplying it by a factor of 1.7 [58]. As $\varepsilon$-martensite is paramagnetic, just like $\gamma$-austenite, it cannot be detected with this magnetic sensor. Furthermore, cross sections of the workpieces were prepared with Beraha II etching agent in order to contrast the martensite needles and thus investigate the distribution of the $\alpha^{\prime}$-martensite in the workpiece surface layer. The images captured with an optical microscope were converted into a binary image. An image processing method [50] utilizing a dilation algorithm [59] and Canny edge detection [60] was used to determine the $\alpha^{\prime}$ martensite distribution inside the workpiece surface layer.

After cryogenic turning, microhardness measurements were carried out using a Vickers indenter with a load force of $100 \mathrm{mN}$ (HV0.01) and loading time of $10 \mathrm{~s}$. The indentations were carried out in a range of 20 to $400 \mu \mathrm{m}$ below the surface in intervals of $10 \mu \mathrm{m}$ to determine microhardness profiles. At each distance, three measuring points were carried out for statistical verification. These indentations were carried out circumferentially at $120^{\circ}$ intervals. The roughness of the cryogenically turned workpieces was measured with a tactile measurement device.

\section{Results and discussion}

\subsection{Thermomechanical load}

The process forces recorded during the cryogenic turning process are shown in Fig. 4. As it was intended, at all test points, the passive forces were the highest component of the resulting force. This can be explained on the one hand by the negative effective rake angle and on the other hand by the elongated cross section of the undeformed chip,

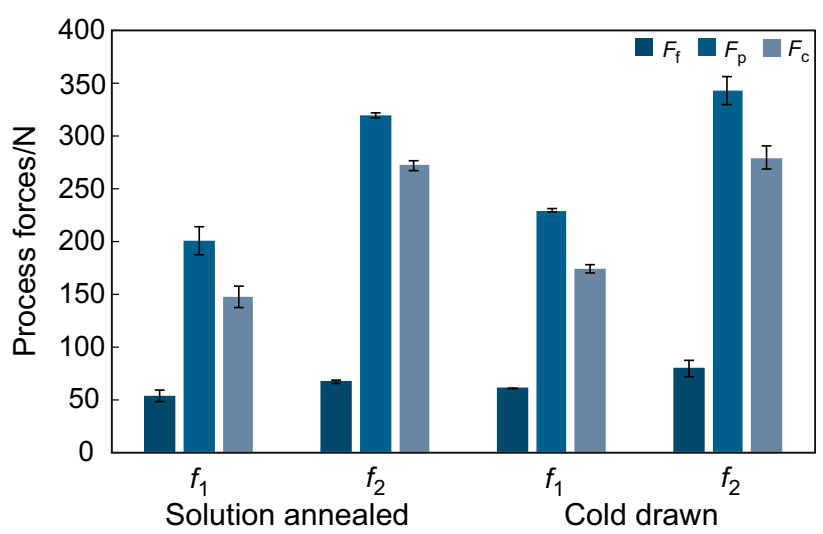

Fig. 4 Process forces when cryogenically turning solution annealed and cold-drawn AISI 347 steels 
since the material was only machined with the corner of the insert. When turning the cold-drawn AISI 347 steel, the process forces were higher compared to the turning experiments on the solution annealed material, which can be attributed to its higher microhardness. However, it is remarkable that although the cold-drawn AISI 347 steel has a 33\% higher microhardness compared to the solution annealed AISI 347 steel, the measured feed forces $F_{\mathrm{f}}$ (directed in feed direction) were just $16 \%$, the passive forces $F_{\mathrm{p}}$ (directed in direction of the tool holder) and the cutting forces $F_{\mathrm{c}}$ (directed in cutting direction) only $11 \%$ higher. Both the solution annealed and the cold-drawn AISI 347 steels showed higher process forces at $f_{2}$ than at $f_{1}$, as the cross section of the undeformed chip was also larger here.

The surface temperatures of the workpieces during the cryogenic turning process are shown in Fig. 5. When turning the cold-drawn AISI 347 steel, higher temperatures were measured. The difference was $30.5 \mathrm{~K}$ at $f_{1}$ and $27.9 \mathrm{~K}$ at $f_{2}$. In the primary shear zone, there are approximately adiabatic conditions [61]; approximately $90 \%$ of the mechanical energy is converted into heat [62]. Higher process forces were measured at $f_{1}$ and $f_{2}$ when machining the cold-drawn AISI 347 steel, and the required mechanical energy was also higher, resulting in a higher heat generation in the primary shear zone and consequently higher workpiece temperatures. The temperatures at $f_{2}$ were higher than that at $f_{1}$, since the coolant can conduct less heat due to the shorter process duration and, in addition, the heat flux from the tool into the workpiece may have been greater at $f_{2}$ than at $f_{1}$ due to the greater cross section of undeformed chip and the higher process forces.

\subsection{Surface topography}

The impact of the feed rate and the initial state of the workpiece material on the surface topography is shown in Fig. 6. Due to the kinematics of the turning process, an

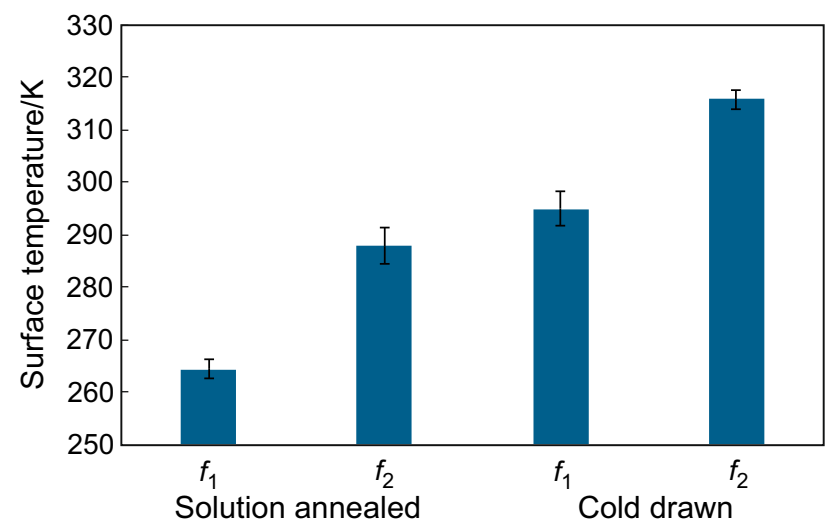

Fig. 5 Surface temperature when cryogenically turning solution annealed and cold-drawn AISI 347 steels

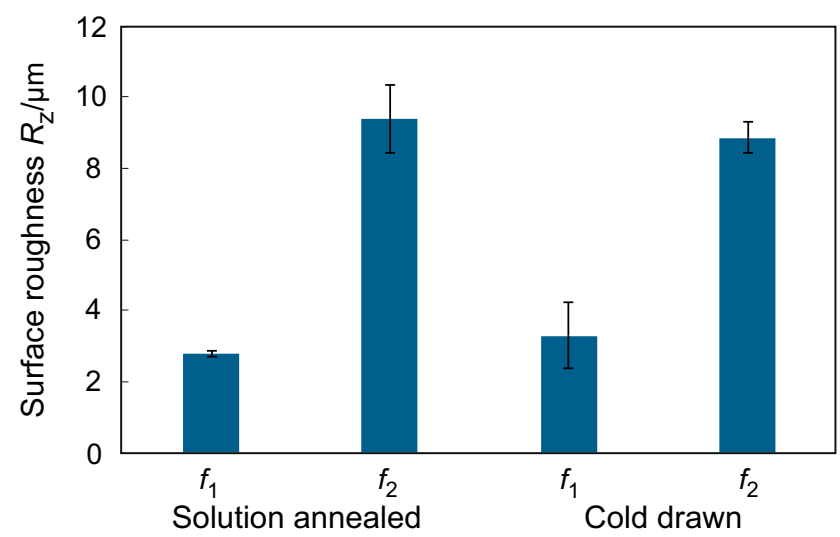

Fig. 6 Average maximum profile height of solution annealed and cold-drawn AISI 347 steels after cryogenic turning

increase in the feed rate leads to a square increase in the average maximum profile height $R_{\mathrm{z}}$ [63]. At $f_{2}$, the measured values agree well with the theoretically calculated average maximum profile height $\left(R_{\mathrm{t}, f_{2}}=9.57 \mu \mathrm{m}\right)$, whereas at $f_{1}$, there were deviations from the theoretical profile height $\left(R_{\mathrm{t}, f_{1}}=1.76 \mu \mathrm{m}\right)$ due to plowing effects. With regard to the initial state of the workpiece material, no significant difference can be observed in the surface topography.

\subsection{Metallurgical properties}

Figure 7 shows the $\alpha^{\prime}$-martensite content of the solution annealed and the cold-drawn workpieces before and after the cryogenic turning process. No ferromagnetic phase components ( $\delta$-ferrite or $\alpha^{\prime}$-martensite) could be detected in the solution annealed AISI 347 steel, so the material was fully austenitic in its initial state (see Fig. 7). After cryogenic turning, 2.2 vol. $\%$ of $\alpha^{\prime}$-martensite was detected in the workpieces turned at $f_{1}$ and 4 vol.\% when turned at $f_{2}$. The content of deformation-induced $\alpha^{\prime}$-martensite was

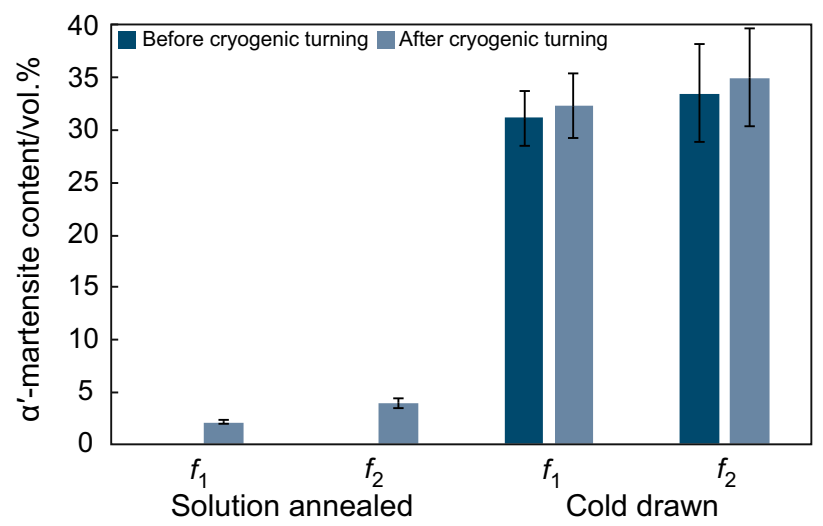

Fig. $7 \alpha^{\prime}$-martensite content of solution annealed and cold-drawn AISI 347 steels before and after cryogenic turning 
(a)

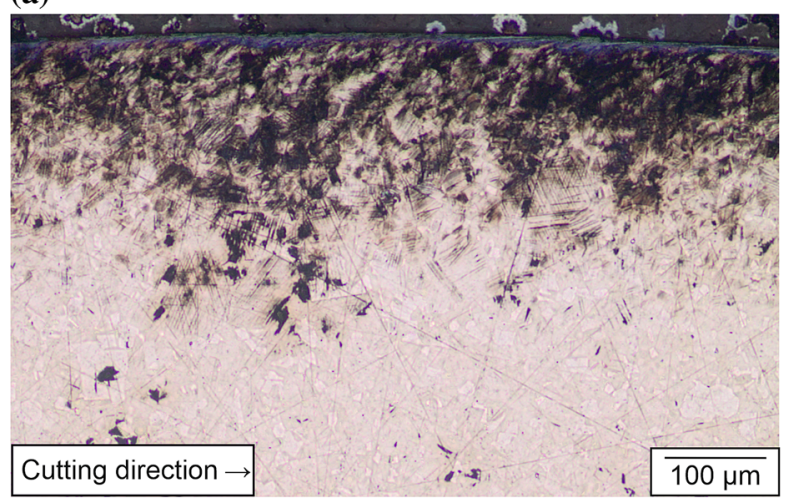

(b)

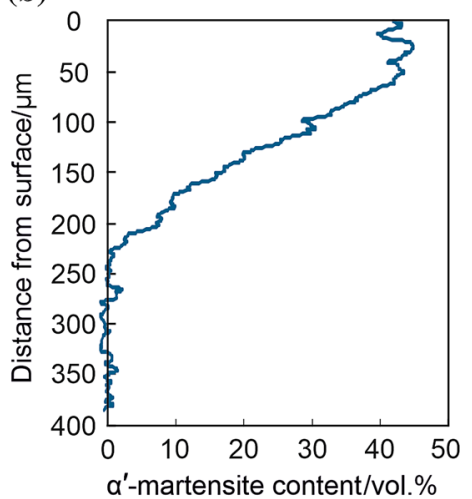

Fig. 8 Optical micrograph of solution annealed AISI 347 steel after cryogenic turning with $f_{2}$ (a) and distribution of $\alpha^{\prime}$-martensite in workpiece surface layer (b)

higher after turning with $f_{2}$, as the passive forces were also higher here (see Fig. 4), and this favored the martensitic phase transformation.

The micrograph of the solution annealed AISI 347 steel (see Fig. 8a) shows that the deformation-induced $\alpha^{\prime}$ martensite (contrasted black) generated during the cryogenic turning process was exclusively located up to a distance of approximately $225 \mu \mathrm{m}$ from the surface. Due to the integral measuring method and the large measuring area of the magnetic sensor, the determined $\alpha^{\prime}$-martensite content was lower (see Fig. 7) than the actual $\alpha^{\prime}$-martensite content in the near-surface area. By means of etching and image processing, an $\alpha^{\prime}$-martensite content of up to approximate $44 \%$ was determined in this area (see Fig. 8 b). However, beyond the depth of approximately $225 \mu \mathrm{m}$, almost no deformation-induced $\alpha^{\prime}$-martensite was detected in the optical microsections. $\alpha^{\prime}$-martensite content determined by image processing on the optical microsection shows only an approximation because the preparation process may also contrast slip and shear bands as well as $\varepsilon-$ martensite, which may have caused an overestimation [64]. While it was difficult to determine the exact phase fractions, nevertheless, this method allowed estimations to be made about $\alpha^{\prime}$-martensite distribution in the workpiece surface layer. However, it can be seen from the near-surface microstructure that the material was strongly plastically deformed in the cutting direction by the turning process. Earlier investigations by Boemke et al. [53] on focused ion beam cuts of cryogenically turned solution annealed AISI 347 steel showed that with $f_{1}$ as well as with $f_{2}$ a nanocrystalline surface layer with a thickness of approximately $10 \mu \mathrm{m}$ was formed.

For the cold-drawn AISI 347 steel, a mean $\alpha^{\prime}$-martensite content of 32.4 vol.\% was measured before cryogenic turning (see Fig. 7). As the deformation-induced $\alpha^{\prime}$ martensite generated during the cryogenic cold drawing was mostly homogeneously distributed in the entire rod material, this measured value should give a fairly good approximation of the actual mean $\alpha^{\prime}$-martensite content in the workpiece microstructure. Since the difference before and after the cryogenic turning process was only in the range of the standard deviation (for both $f_{1}$ and $f_{2}$ ), it cannot be verified whether deformation-induced phase transformation occurred in the surface layer during the cryogenic turning of the cold-drawn AISI 347 steel, based on these measurement results (see Fig. 7).

In optical micrographs of the cold-drawn AISI 347 steel turned with $f_{2}$, a bright layer with a thickness of approximately $25 \mu \mathrm{m}$ was noticeable at the surface (see Fig. 9b). This nanocrystalline surface layer has such a small grain size that it was not contrasted by the etching agent. Therefore, no statements can be made about the $\alpha^{\prime}$ martensite content in this layer. The cold-drawn AISI 347 steel turned with $f_{1}$ also exhibited a nanocrystalline surface layer, which was, however, much less pronounced (see Fig. 9a). The layer thickness varied in a range between 0 and $10 \mu \mathrm{m}$.

In regard to the phase fractions, the microstructure in the surface layer was very similar compared to the

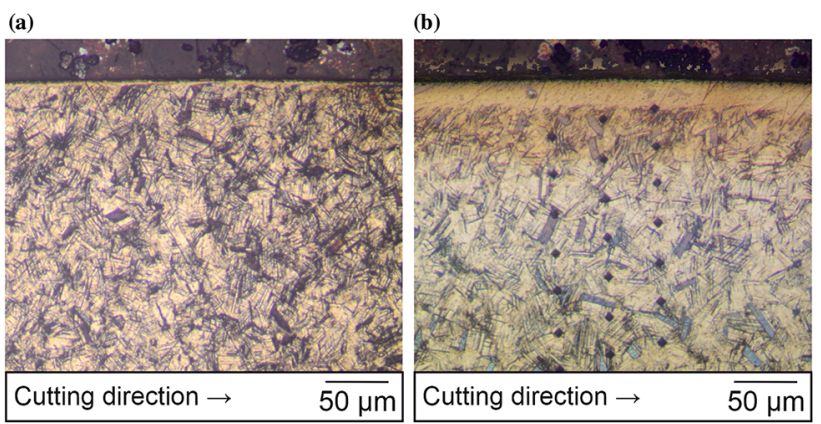

Fig. 9 Optical micrographs of workpiece surface layer of cold-drawn AISI 347 steel after cryogenic turning with $f_{1}$ (a) and $f_{2}$ (b) 
microstructure before turning (see Fig. 2b). A higher $\alpha^{\prime}$ martensite content in the near-surface area caused by the cryogenic turning processes cannot be detected. Based on the measurements taken with the magentic sensor (see Fig. 7) and the optical micrographs (see Fig. 9), it can be concluded that the cryogenic turning of the cold-drawn AISI 347 steel did not cause a significant deformationinduced phase transformation. The first possible cause for this was the higher temperature (see Fig. 5) during the turning process, compared to the turning process with the solution annealed AISI 347 steel, which may have partially inhibited the phase transformation. A second possible reason for this was that $\alpha^{\prime}$-martensite content was already very high at 32.4 vol. $\%$ before the cryogenic turning due to the cold drawing process. Continuous casting usually does not lead to a homogeneous distribution of the chemical elements in the rod material [65]. Due to the heterogeneities in the chemical composition and the grain sizes, different austenitic grains have different austenite stability $[6,30]$. It can be assumed that in cold drawing, the grains with lower austenite stability transformed into $\alpha^{\prime}$-martensite, whereas the austenitic grains with higher austenite stability still existed without phase transformation after the cold drawing process. Thus, the austenitic matrix remaining after cold drawing had a higher average austenite stability than that of the solution annealed AISI 347 steel. It is also conceivable that the grain refinement associated with the cold drawing process led to a further increase in austenite stability. Due to this higher austenite stability in superposition with the higher thermal load (see Fig. 5) at only slightly higher mechanical loads (see Fig. 4), there was no significant increase in deformation-induced $\alpha^{\prime}$ martensite in the cold-drawn AISI 347 after cryogenic turning.

The plastic deformation of the microstructure below the nanocrystalline surface layer in cutting direction was less pronounced compared to the solution annealed AISI 347 steel (see Fig. 8a). This can be explained by the fact that the material behaved less ductile after the cold drawing process due to the changed mechanical properties and thus deformed less when a similar mechanical load was applied.

\subsection{Microhardness}

Microhardness measurements were used to evaluate the mechanical properties of the workpiece surface layer (see Fig. 10). The changes in the microhardness compared to the properties of the bulk material were a direct effect of the metallurgical changes in the microstructure due to the cryogenic turning process. Both the solution annealed and the cold-drawn AISI 347 steel had a higher hardness in the near-surface area than in the bulk material. The increase in hardness of the cryogenically turned solution annealed
AISI 347 steel is due to strain hardening and deformationinduced phase transformation from $\gamma$-austenite to $\alpha^{\prime}$ martensite. However, in cold-drawn AISI 347 steel, which already contained large amounts of $\alpha^{\prime}$-martensite before cryogenic turning, the increase in hardness after cryogenic turning was mainly due to strain hardening, since no deformation-induced $\alpha^{\prime}$-martensite formation caused by the turning process was detected (see Figs. 7, 9).

The increase in hardness of the solution annealed AISI 347 steel was approximate $67 \%$ at both $f_{1}$ and $f_{2}$. The higher hardness penetration depth at $f_{2}$ was already observed in earlier investigation [51] and can mainly be attributed to the higher content of $\alpha^{\prime}$-martensite in the surface layer. The increase in hardness for cold-drawn AISI 347 steel was only $21 \%$ for $f_{1}$ and $35 \%$ for $f_{2}$ compared to the bulk hardeness of $280 \mathrm{HV} 0.01$. The higher hardness at $f_{2}$ was due to the significantly higher hardness measured at the outermost indentations at a distance from the surface of $20 \mu \mathrm{m}$, which were partly located within the nanocrystalline surface layer (see Fig. 9b). With the exception of this test point, the microhardness profile was very similar to that of the cold-drawn AISI 347 steel turned with $f_{1}$. The maximum achievable microhardness for cold-drawn AISI 347 steel turned with $f_{2}$ was approximately 380 HV0.01, and therefore slightly higher than that for solution annealed AISI 347 steel turned with $f_{2}$ (approximately 350 HV0.01). For $f_{1}$, the maximum microhardness for solution annealed AISI 347 steel was the same as that for cold-drawn AISI 347 steel at also approximately $350 \mathrm{HV} 0.01$.

The hardness penetration depth after cryogenic turning of the solution annealed AISI 347 steel was significantly higher than that of the cold-drawn AISI 347 steel, as the material was more plastically deformed during machining and thus pronounced strain hardening as well as deformation-induced $\alpha^{\prime}$-martensite formation occurred in the affected region in a distance of up to approximately $225 \mu \mathrm{m}$ from the surface (see Fig. 8). Beyond this nearsurface area, the cryogenically turned solution annealed AISI 347 steel had a much lower hardness than the colddrawn AISI 347 steel. It is worth mentioning that the increase in microhardness in the solution annealed AISI 347 steel due to the cryogenic turning process was significantly higher (210 HV0.01 $\rightarrow 350$ HV0.01) compared to the cold drawing process without subsequent cryogenic turning (210 HV0.01 $\rightarrow 280$ HV0.01). Since both the surface layer of the solution annealed AISI 347 steel and the core material of the cold-drawn AISI 347 steel had a high $\alpha^{\prime}$-martensite content (see Figs. 7,8 ), the significantly higher increase in microhardness when cryogenically turning the solution annealed AISI 347 steel can mainly be explained by the stronger plastic deformation in the surface layer and the resulting strain hardening. The slightly higher $\alpha^{\prime}$-martensite content in the surface layer of the solution 

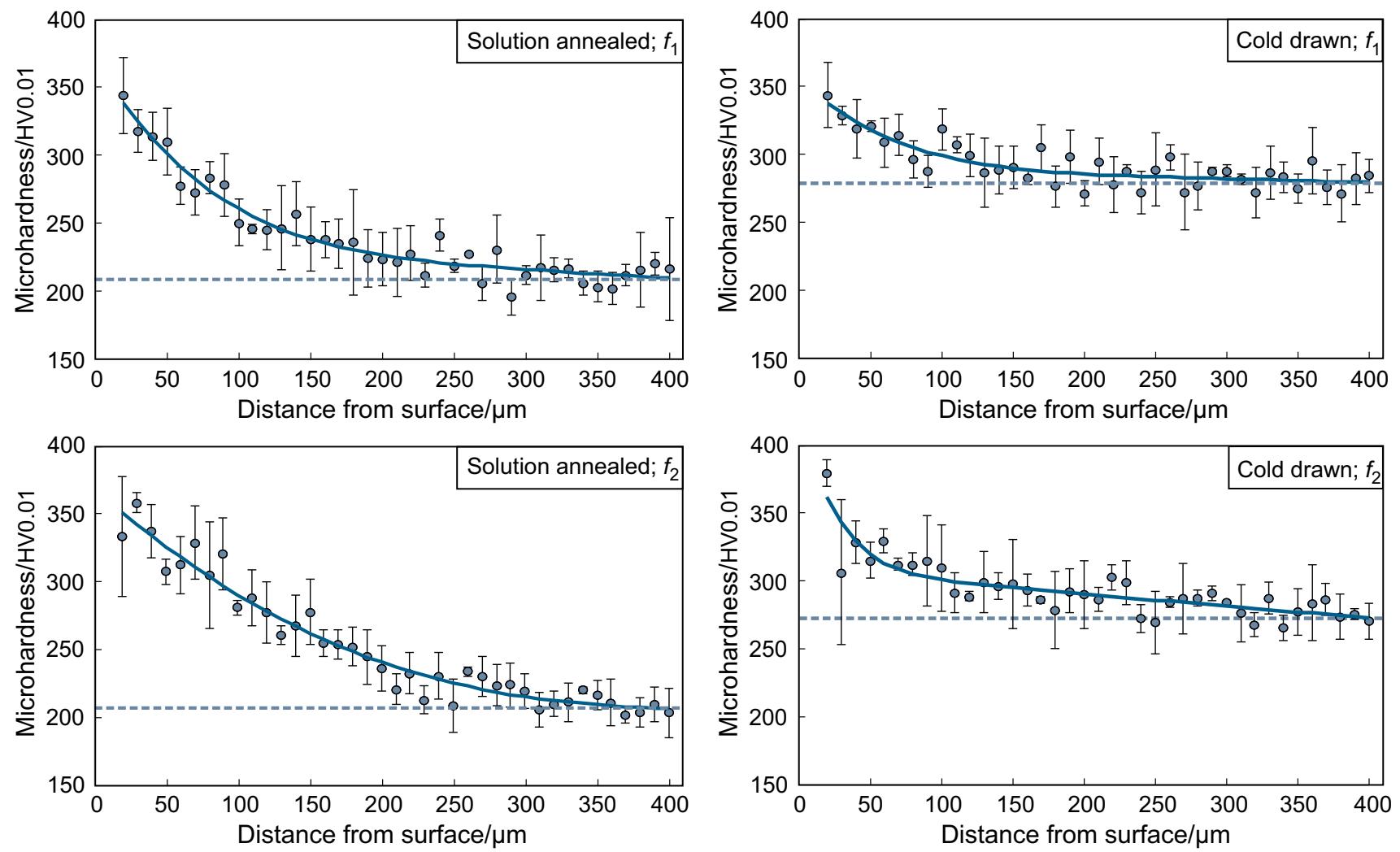

Fig. 10 Microhardness profiles of solution annealed and cold-drawn AISI 347 steel after cryogenic turning

annealed AISI 347 steel (up to $44 \%$ compared to $32 \%$ ) may also have contributed to the higher increase in microhardness.

The similar microhardness values between the colddrawn and solution annealed AISI 347 steel in the nearsurface area may also be a possible explanation for the results of the force measurements. Although, before turning, the microhardness of the cold-drawn AISI 347 steel was $33 \%$ higher than that of the solution annealed AISI 347 steel, the passive forces and cutting forces were only approximately $11 \%$ higher (see Fig. 4). During the cryogenic turning process, a significant proportion of the strain hardening and also of the deformation-induced $\alpha^{\prime}$-martensite formation for the solution annealed AISI 347 steel takes place before the material separation in the preliminary deformation zone. Thus, the pronounced strain hardening and the formation of deformation-induced $\alpha^{\prime}$ martensite in the preliminary deformation zone could cause that the solution annealed AISI 347 steel had similar mechanical properties like the cold-drawn AISI 347 steel when the primary shear zone was reached, resulting in similar process forces. In order to investigate this in more detail, cryogenic turning experiments with a quick-stopdevice will be carried out in the future. After the rapid cutting interruption during cryogenic turning, cross sections of the preliminary deformation zone can be made in order to investigate the microstructure and hardness. This allows conclusions to be made on the development of strain hardening and the deformation-induced formation of $\alpha^{\prime}$ martensite during the cryogenic turning process.

\section{Conclusions and outlook}

This paper presents a newly developed process chain for the manufacture of hardened components from metastable austenitic steel. The solution annealed austenitic AISI 347 steel was cold-drawn at deep cryogenic temperatures in order to harden it before machining. The hardness increase resulted from a superposition of strain hardening and deformation-induced phase transformation from $\gamma$-austenite to $\alpha^{\prime}$-martensite. The hardness of the surface layer was then further increased in a cryogenic turning process, while the component was simultaneously machined to its final geometry. This newly developed process chain was compared with an approved cryogenic turning process on solution annealed AISI 347 steel. The feed rate was varied in order to modify the thermomechanical load in the surface layer during the cryogenic turning process. The remaining process parameters, tool properties and cooling strategy were kept constant. 
The solution annealed AISI 347 steel was purely austenitic and had an initial hardness of approximately 210 HV0.01. After cold drawing, the material had an $\alpha^{\prime}$ martensite content of $32.4 \%$ and a hardness of approximately 280 HV0.01. Higher temperatures and slightly higher process forces were measured when turning the cold-drawn AISI 347 steel compared to turning the solution annealed AISI 347 steel. After cryogenic turning the solution annealed AISI 347 steel, deformation-induced $\alpha^{\prime}$ martensite was generated in the near-surface area up to a distance of approximately $225 \mu \mathrm{m}$ from the surface due to high mechanical and low thermal loads. However, no additional deformation-induced $\alpha^{\prime}$-martensite was detected in the surface layer of the cold-drawn AISI 347 steel after cryogenic turning. This was attributed to the higher temperatures and the higher austenite stability of the austenite that retained after the cold drawing process.

The cryogenic turning led to a strong surface hardening of the solution annealed AISI 347 steel due to strain hardening and deformation-induced phase transformation. Beyond this near-surface area, the cryogenically turned solution annealed AISI 347 steel had a ductile core with low hardness. After cryogenic turning, the cold-drawn AISI 347 steel had a similar maximum hardness in the surface layer as the solution annealed AISI 347 steel as both had a similar amount of $\alpha^{\prime}$-martensite in the near-surface area and both were strain hardened during the turning process. However, the cold-drawn AISI 347 steel also exhibited a higher bulk hardness. No significant differences could be observed with regard to the surface topography. The cryogenic turning process on the solution annealed AISI 347 steel led to a significantly higher increase in microhardness than cold drawing alone.

As the cryogenic turning of the solution annealed AISI 347 steel resulted in a similar near-surface layer hardening and also a similar surface topography, it can be concluded that the additional process step of cold drawing did not yield any significant improvements in the resulting surface morphology. Based on the results shown in this paper, we recommend cryogenic turning in solution annealed condition for industrial applications, as it can be easily integrated into the process chain, leads to pronounced surface hardening and renders a separate hardening process like shot peening obsolete.

In future investigations, cryogenic turning experiments with a quick-stop-device will be carried out to investigate the hardening mechanisms in more detail. Furthermore, the fatigue behavior of cold-drawn and cryogenically turned specimen will be investigated.

Acknowledgements This work is funded by the Deutsche Forschungsgemeinschaft (DFG, German Research Foundation, No. 172116086 - SFB 926). We would like to thank Prof. T. Beck, Dr.
M. Smaga and A. Boemke from the Institute of Materials Science and Engineering of the University of Kaiserslautern for performing the cold drawing of the workpiece material. Naming of specific manufacturers is done solely for the sake of completeness and does not necessarily imply an endorsement of the named companies nor that the products are necessarily the best for the purpose.

Open Access This article is distributed under the terms of the Creative Commons Attribution 4.0 International License (http://crea tivecommons.org/licenses/by/4.0/), which permits unrestricted use, distribution, and reproduction in any medium, provided you give appropriate credit to the original author(s) and the source, provide a link to the Creative Commons license, and indicate if changes were made.

\section{References}

[1] C. Pasel, Manufacture of components (firearms, turbine blades, etc.) requiring high resistance to corrosion, besides thermal heat treatment process, Reichspatent 304126, Essen, Germany, 1912.

[2] P. Marshall, Austenitic stainless steels - microstructure and mechanical properties, Elsevier Applied Science Publishers, London and New York, 1984.

[3] G. Hunscha, R. Grundmann, I. Stellfeld, K. Michel, P. Roth, A. Paus, H. Ordenbach, G. Butzmann, A. Steiner, K. Werny, W. Borges, G. Montag, in: V.D. Eisenhüttenleute VDEh (Eds.), Nichtrostende Stähle, 2nd ed., Verlag Stahleisen mbH, Düsseldorf, Germany, 1989, pp. 243-299.

[4] H. Becker, in: V.D. Eisenhüttenleute VDEh (Eds.), Nichtrostende Stähle, 2nd ed., Verlag Stahleisen $\mathrm{mbH}$, Düsseldorf, Germany, 1989, pp. 1-15.

[5] R.T. Loto, C.A. Loto, I. Ohijeagbon, Results Phys. 11 (2018) 570-576.

[6] J. Man, M. Smaga, I. Kubêna, D. Eifler, J. Polák, Eng. Fract. Mech. 185 (2017) 139-159.

[7] X. Chen, J. Li, X. Cheng, H. Wang, Z. Huang, Mater. Sci. Eng. A 715 (2018) 307-314.

[8] I.S. Jawahir, E. Brinksmeier, R. M'Saoubi, D.K. Aspinwall, J.C. Outeiro, D. Meyer, D. Umbrello, A.D. Jayal, CIRP Annals 60 (2011) 603-626.

[9] S. Jung, Contribution to the influence of the surface characteristics on the tribological system radial shaft seal, University of Stuttgart, Stuttgart, Germany, 2012.

[10] D. Frölich, B. Magyar, B. Sauer, P. Mayer, B. Kirsch, J.C. Aurich, R. Skorupski, M. Smaga, T. Beck, D. Eifler, Wear 328-329 (2015) 123-131.

[11] J.Y. Yun, G.S. Shin, D.H. Hur, W.S. Kang, C.H. Bae, S.J. Kim, Wear 368-369 (2016) 124-131.

[12] B. Boardman, ASM handbook, ASM International, Materials Park Ohio, USA, 1990, pp. 673-688.

[13] H. Mughrabi, B. Donth, G. Vetter, Fatigue Fract. Eng. Mater. Struct. 20 (1997) 595-604.

[14] S. Bagherifard, S. Slawik, I. Fernández-Pariente, C. Pauly, F. Mücklich, M. Guagliano, Mater. Des. 102 (2016) 68-77.

[15] H.K. Yi, F.K. Yan, N.R. Tao, K. Lu, Scripta Mater. 114 (2016) $133-136$.

[16] C. Lei, X. Deng, X. Li, Z. Wang, G. Wang, R.D.K. Misra, J. Alloy. Compd. 689 (2016) 718-725.

[17] I. Nikitin, B. Scholtes, J. Heat Treat. Mater. 67 (2012) 188-194.

[18] K. Yvell, T.M. Grehk, G. Engberg, Mater. Charact. 122 (2016) $14-21$.

[19] J. Peng, K. Li, Q. Dai, J. Peng, Results Phys. 10 (2018) 187-193.

[20] A. Weidner, U.D. Hangen, H. Biermann, Philos. Mag. Lett. 94 (2014) 522-530. 
[21] R. Skorupski, Influence of near-surface deformation-induced martensite formation on LCF and HCF fatigue behavior and wear behavior of the metastable austenitic steel AISI 347, Universität Kaiserslautern, Kaiserslautern, Germany, 2017.

[22] W. Han, Y. Liu, F. Wan, O. Liu, X. Yi, Q. Zhan, D. Morrall, S. Ohnuki, J. Nucl. Mater. 504 (2018) 29-32.

[23] G.B. Olson, M. Cohen, Met. Mater. Trans. A 6 (1975) 791-795.

[24] S.S. Hecker, M.G. Stout, K.P. Staudhammer, J.L. Smith, Met. Mater. Trans. A 1 (1982) 619-626.

[25] C.M. Wayman, H.K.D.H. Bhadeshia, Physical metallurgy, Elsevier Ltd. All, North Holland, 1996.

[26] G.C. Eichelmann, T.C. Hull, Trans. Am. Soc. Met. 45 (1953) 77-104.

[27] N. Nakada, H. Ito, Y. Matsuoka, T. Tsuchiyama, S. Takaki, Acta Mater. 58 (2010) 895-903.

[28] T. Angel, Journal of the Iron and Steel Institute 177 (1954) $165-174$.

[29] H. Becker, H. Brandis, W. Küppers, Thyssen Edelstähle Technische Berichte 12 (1986) 35-54.

[30] K. Nohara, Y. Ono, N. Ohashi, Tetsu-to-Hagane 63 (1977) 212-222.

[31] G.S. Raman, K.A. Padmanabhan, Mater. Sci. Technol. 10 (1994) 614-620.

[32] D. Meyer, CIRP Annals 61 (2012) 543-546.

[33] E. Brinksmeier, F. Klocke, D.A. Lucca, J. Sölter, D. Meyer, Procedia CIRP 13 (2014) 429-434.

[34] I. Horowitz, Surface treatment with blasting abrasives - manual about blasting technology and blasting systems - Volume 1: the basics of blasting technology, Vulkan-Verlag, Essen, Germany, 1982.

[35] V. Schulze, F. Bleicher, P. Groche, Y.B. Guo, Y.S. Pyun, CIRP Annals 65 (2016) 809-832.

[36] E. Brinksmeier, M. Garbrecht, D. Meyer, CIRP Annals 57 (2008) 541-544.

[37] V. Shrinivas, S.K. Varma, L.E. Murr, Met. Mater. Trans. A 26 (1995) 661-671.

[38] G. Fargas, J.J. Roa, A. Mateo, Mater. Sci. Eng. A 641 (2015) 290-296.

[39] A. Nakonieczny, A. Ciski, T. Babul, BHM Berg- und Hüttenmännische Monatshefte 155 (2010) 105-109.

[40] G. Singh, S.S. Gill, M. Dogra, J. Clean. Product. 143 (2017) 1060-1068.

[41] P. Baldissera, Mater. Des. 31 (2010) 4725-4730.

[42] V.L. De la Concepción, H.N. Larusso, H.G. Svoboda, Proceed. Mater. Sci. 8 (2015) 1047-1056.

[43] M. Novelli, J.J. Fundenberger, P. Bocher, T. Grosdidier, Appl. Surf. Sci. 389 (2016) 1169-1174.
[44] P. Mallick. N.K. Tewary, S.K. Ghosh, P.P. Chattopadhyay, Mater. Charact. 133 (2017) 77-86.

[45] Y. Xiong, T. He, J. Wang, Y. Lu, L. Chen, F. Ren, Y. Liu, A.A. Volinsky, Mater. Des. 88 (2015) 398-405.

[46] R. Singh, D. Sachan, R. Verma, S. Goel, R. Jayaganthan, A. Kumar, Mater. Today Proc. 5 (2018) 16880-16886.

[47] Y. Xiong, Y. Yue, Y. Lu, T. He, M. Fan, F. Ren, W. Cao, Mater. Sci. Eng. A 709 (2018) 270-276.

[48] J.C. Aurich, P. Mayer, B. Kirsch, D. Eifler, M. Smaga, R. Skorupski, CIRP Annals 63 (2014) 65-68.

[49] I.S. Jawahir, H. Attia, D. Biermann, J. Duflou, F. Klocke, D. Meyer, S.T. Newman, F. Pusavec, M. Putz, J. Rech, V. Schulze, D. Umbrello, CIRP Annals 65 (2016) 713-736.

[50] P. Mayer, B. Kirsch, C. Müller, H. Hotz, R. Müller, S. Becker, E. von Harbou, R. Skorupski, A. Boemke, M. Smaga, D. Eifler, T. Beck, J.C. Aurich, CIRP J. Manuf. Sci. Technol. 23 (2018) 6-19.

[51] H. Hotz, B. Kirsch, S. Gutwein, S. Becker, E. von Harbou, R. Müller, J.C. Aurich, wt. Werkstattstechnik online 108 (2018) $12-17$.

[52] B. Kirsch, H. Hotz, R. Müller, S. Becker, A. Boemke, M. Smaga, T. Beck, J.C. Aurich, Product. Eng. 13 (2019) 343-350.

[53] A. Boemke, M. Smaga, T. Beck, MATEC Web Conf. 165 (2018) 20008.

[54] C.R. Barber, British J. Appl. Phys. 17 (1966) 391-397.

[55] H. Hotz, B. Kirsch, S. Becker, E. von Harbou, R. Müller, J.C. Aurich, Procedia CIRP 77 (2018) 207-210.

[56] S. Becker, H. Hotz, B. Kirsch, J.C. Aurich, E. von Harbou, R. Müller, J. Manuf. Sci. Eng. 140 (2018) 101016.

[57] P. Mayer, R. Skorupski, M. Smaga, D. Eifler, J.C. Aurich, Procedia CIRP 14 (2014) 101-106.

[58] J. Talonen, H. Hänninen, P. Nenonen, G. Pape, Met. Mater. Trans. A 36 (2005) 421-432.

[59] R. van den Boomgaard, R. van Balen, CVGIP-Graph. Model. Im. 54 (1992) 252-258.

[60] J. Canny, IEEE Trans. Pattern Anal. Mach. Intell. 8 (1986) 679-698.

[61] F. Zhou, X. Wang, Y. Hu, L. Ling, Int. J. Therm. Sci. 73 (2013) 38-45.

[62] G.I. Taylor, H. Quinney, Proceedings of the Royal Society of London, Ser. A, 143 (1934) 307-326.

[63] P.H. Brammertz, Industrie-Anzeiger 2 (1961) 25-32.

[64] C. Celada-Casero, H. Kooiker, M. Groen, J. Post, D. San-Martin, Metals 7 (2017) 271.

[65] J. Man, I. Kubêna, M. Smaga, O. Man, A. Järvenpää, A. Weidner, Z. Chlup, J. Polák, Procedia Stuctural Integrity 2 (2016) 2299-2306. 